\title{
Learning styles and organisational development in practice: an exploratory study of how learning styles and individual learning strategies can facilitate organisational development
}

\author{
Fuglesangs Alle 4, \\ DK-8210 Aarhus V, Denmark \\ E-mail: jabk@asb.dk \\ E-mail:kml@asb.dk \\ *Corresponding author
}

Jacob Brix* and Karen M. Lauridsen

Aarhus University, Business and Social Sciences,

\begin{abstract}
Issues of innovation and knowledge management are often treated from an organisational learning perspective. As a complement to this, there is a vast potential in the strategic enhancement of individual learning by implementing learning styles profiles and creating personal learning strategies for management and employees in a knowledge-based organisation. Based on an action-research case study, we offer an example of how learning styles affects individual learning and thus personal knowledge creation in practice. The paper argues that innovation and knowledge management is enhanced and facilitated in practice by working with the learning styles of individuals and groups/teams.
\end{abstract}

Keywords: learning styles; personal knowledge management; organisational development; learning; incremental innovation.

Reference to this paper should be made as follows: Brix, J. and Lauridsen, K.M. (2012) 'Learning styles and organisational development in practice: an exploratory study of how learning styles and individual learning strategies can facilitate organisational development', Int. J. Innovation and Learning, Vol. 12, No. 2, pp.181-196.

Biographical notes: Jacob Brix is an Industrial $\mathrm{PhD}$ student at the Aarhus School of Business and Social Sciences, Aarhus University. He is affiliated with the Danish Technological Institute's Centre for Innovation. He has a Master's degree in Corporate Communication and he is a certified Dunn and Dunn Learning Styles Trainer and Qualified Building Excellence Trainer.

Karen M. Lauridsen is an Associate Professor who works with knowledge generation, learning and learning styles. Her current research focuses on the multilingual and multicultural classroom at the International University, including the challenges of teaching and learning through the medium of a foreign language. She is a Building Excellence Master Trainer. 


\section{Introduction}

Knowledge-based organisations (KBOs) wish to be innovative. A recent Scandinavian survey demonstrates this, because around $42 \%$ of the managers and employees asked stated that it is 'very important' to be innovative. However, only an average of $16 \%$ of them have formal procedures in place for working with innovation and hence knowledge management in a strategic perspective (INNOVATIONinside, 2010; cf. also Drejer, 2008). Until now, an individual learning perspective has typically not been addressed or articulated in KBO-internal processes in practice (cf. Camuffo and Comacchio, 2004) but rather, when time is available, the locus of individual learning is supposed to be external courses (Belling et al., 2004; Cavaleri and Seivert, 2005). It is not to say that individual learning is an unexplored theme (i.e., Lehesvirta, 2004; Stacey, 2003), but the interplay between individual learning and its effects on incremental innovation in internal work processes (Leonard, 1998), which we in our paper refer to as organisational development, is a key area of interest lacking empirical research evidence (Anderson et al., 2004; Crossan and Apaydin, 2010). In this context, a focus on the implementation of individual learning strategies and the articulation of these strategies in a group/team context is needed in order to assist managers and employees in creating organisational development (cf. Kjelgaard, 2009), and in a wider perspective to harness the potential for future innovation in general (Belling et al., 2004; Fagerberg, 2005; Lehesvirta, 2004).

In this paper, we include the dimension of individual learning and its implications for organisational development, namely individual learning strategies derived from individual learning styles profiles [for more details, see Section 5; Dunn and Griggs (2007) and Dunn and Rundle, (2007)]. The new dimension combined with our four-month clinical-inquiry action-research methodology (Bradbury and Rearson, 2008; Gnauer, 2010) has resulted in unique multidimensional data which through our analysis gives us new important perspectives for organisational development and allows us to avoid a one-dimensional perspective on innovation, as criticised by Anderson et al. (2004) and Fagerberg (2005). As a result, we set up as hypothesis that the application of learning styles can positively affect individual learning, and thereby enhance collaboration and communication in a group/team context, resulting in the incremental process innovation we refer to as organisational development.

\section{Premise}

In practice, employees and managers in KBOs often work under a constant time pressure and only little, if any, time is formally set aside for reflection or development of new ideas (Argyris, 1991; Galavan et al., 2008; Sabri, 2005; Stadil and Waldstrøm, 2009). When time is not set aside for reflection, it is an unwise move on the part of the KBOs because the very key to learning and thus personal knowledge creation is by means of reflection (Damasio, 2006; Davenport and Prusak, 1998; Restak, 2003). In addition, the creation of intra- and interpersonal insights is often taken for granted in the strategic view of knowledge management; top management does not emphasise the improvement of collaboration and teamwork and thereby the enhancement of social intelligence and information sharing capabilities (Argyris, 1990; Daghfous, 2004; Davenport and Prusak, 1998; Kotter, 1999; Schultz, 2005). As a consequence of this, it is imperative to divert focus to the aspect of individual learning in an organisational setting (Easterby-Smith and 
Lyles, 2005) because individual learning and organisational development are intertwined (cf. Elkjaer, 2005; Goldman et al., 2009). Thus, when working strategically with knowledge management, the inclusion of an individual learning perspective creates the foundation for successful initiatives in the organisational setting (Wiig, 1993). This view is strengthened by Lauridsen (2010) who states that "learning does not only occur in classrooms, but everywhere and whenever something new is to be learned or an old routine has to be changed and recreated" [Lauridsen (2010, p.10) authors' translation].

The arguments for focusing on individual learning and individual learning strategies mentioned above are also addressed by multiple organisational psychologists, e.g., Hogg and Vaughan (2008), Kaufmann and Kaufmann (2008), and Schein (2004) who emphasise that paying attention to the individual and how the individual person works in a group and how the group/team affects the individual when working, will enhance collaboration, communication and thus the social working environment in organisations (Billett, 2002). Hence, the foundation of successful strategic knowledge management initiatives in organisations needs a strengthened understanding of the importance of individual learning strategies and the proactive use of these when working, especially with organisational development (also cf. Higgins and Mirza, 2010). With the insights derived from the individual learning strategies, and by using the individual learning strategies to create intra- and interpersonal insights in the KBOs, the gap between the desired and the actual outcome of the knowledge management initiatives will close, leading towards a higher rate of success in the innovation processes due to enhanced communication and collaboration amongst co-workers (Argyris, 1991; Goleman et al., 2004; Kotter, 1999; Pegels, 1998).

\section{Methodology}

The range of empirical studies regarding innovation processes in practice have exploded during the last couple of decades (Crossan and Apaydin, 2010), and this tendency has shown no sign of diminishing. However, the vast majority of existing research discusses and concludes on one-dimensional perspectives of the innovation process in practice which can result in the danger of 'routinisation of the innovation research' (Anderson et al., 2004) and thus keep the research in a myopically directed perspective. It goes without saying that the one-dimensional research approaches have contributed immensely to the understanding of innovation in both research and in practice, but still the very creation of innovation remains an enigma (Fagerberg, 2005).

In the light of this we chose to apply Schein's clinical inquiry action research to our study (Bradbury and Rearson, 2007; Schein, 2004). The clinical inquiry action research is a scientific orientation of inquiry where participation in and exploration of organisational practices and processes are understood at first hand by the researcher(s) (ibid.). Hence, full participation is required in all processes to collect valid data together with the possibility of creating emancipatory interventions where current processes are rethought and changed by removing all basic assumptions and taken-for-granted perceptions in the organisational culture and business processes (Eden and Huxham, 1996). In our study we participated on a daily basis in the work at the unit of analysis in a period of four months, gathering data both by observing, questioning and participating in the actual work at the unit of analysis, resulting in a first hand understanding of the full work processes and the culture in which the work was done (cf. also Gnauer, 2010). During the action research 
process we made several interventions with staff and management based on a learning dialogue, where the existing work processes were critically reflected upon (ibid.). Finally, staff and management validated the value of our interventions in order to create well-founded conclusions of the action research (Workman, 2007). Two general norms follow the action research orientation: First of all, research is effectuated as an ongoing iterative and progressive process where adaptation is required according to the concurrent findings (cf. Bradbury and Rearson, 2007; Schein, 2004). In short, the authors could not set up parameters for research beforehand or know what would emerge during the participatory research method. For this reason, this paper describes and analyses only one of the interventions made during our research period, and the paper is henceforth delimited to analyse this intervention with the complete research data regarding the observations we made during our study. Secondly, statistics is not required to validate the conclusions because the means of validation used in the natural sciences do not fit questions about the development of human thinking and acting. Hence, the scientific orientation seeks to create functional solutions for organisational practice, and the verification process is completed in cooperation with the clinical inquirer and the organisation being researched (Bradbury and Rearson, 2007; Eden and Huxham, 1996; Schein, 2004). Finally, the conclusions deriving from action research are bound in the historical and culturally specific context in which they have been constructed (Anderson, 1995; Burr, 2001).

\section{Ontological foundation}

The study is founded in a social constructionist ontology since a critical emancipatory stance toward the concept of knowledge management is required. The social constructionist ontology suggests that taken-for-granted assumptions (Burr, 2001) about what is real should be removed and reconsidered in order to eliminate Einstellung (Eysenck and Keane, 2007) which is a state of mind where habituation of problemsolving and/or job performance lead to a blind attitude towards new ways of thinking and thus create a tunnel view for the employees that prevent them from creating incremental innovation in the business processes (Drucker, 1993). When critically questioning the existing Einstellung in practice, the path for future innovative development and new ways of thinking is thus cleared (Blackman and Murray, 2006; Da Bono, 1970; Garrido, 2009; Tushman and Anderson, 1997). Although a social constructionist stand is taken, it is in its less rigorous form of essentialism (Burr, 2001). The essentialist view argues that all individuals have their own personality and that personal essence is present in all human beings. Knowledge and the truth(s) about knowledge are constructed socially, and it is thus possible to have multiple truths. Likewise, the juxtapositioning of opposite truths is becoming generally accepted (cf. Firat and Venkatesh, 1995) which, e.g., is demonstrated in practice by the emergence of new and successful business models in saturated markets (Lee and Chang, 2007; Gottschalk, 2006). In sum, what is accepted as a right and useful process for one $\mathrm{KBO}$ can be found impeding and henceforth false by another similar KBO (Davenport, 2005; Drejer, 2008).

Because we argue that every truth is a subjective evaluation based on emotions as well as reasoning, we stress that the Cartesian dualism (Damasio, 2006; Warburton, 2006) should not be taken into consideration in a study taking its point of departure in the action research orientation. Descartes stated that the creation of objectivity was possible 
by leaving out emotions during an evaluation process (Damasio, 2006; Warburton, 2006). Contrary to Descartes, we argue that the accomplishment of objectivity is not possible and that, instead, it is appropriate to evaluate and reflect upon the processes and methods that result in successful practices and to subsequently draw conclusions based on a learning dialogue with the members of the organisation being studied (Damasio, 2006; Elkjaer, 2005; Klingberg, 2009; Restak, 2003; Scharmer, 2009).

\section{Data - information - personal knowledge management}

When initiating a strategic perspective on knowledge and innovation management, it is necessary to make a clear distinction between the concepts of data, information and knowledge (Davenport and Prusak, 1998). Many practitioners - and also academics - use these concepts interchangeably without distinguishing between the data or information carriers on the one hand and knowledge as a result of individual learning processes on the other (cf. e.g., Kjelgaard, 2009; Lauridsen and Lauridsen, 2009). Hence, it is argued that the work of Kastberg et al. (2007) coining the concept of personal knowledge management is utterly important because organisational development is inhibited unless we change perspective from the educational paradigm focusing on a sender and a receiver of objectified knowledge (Correa Da Silva and Agusti-Cullell, 2008) to a learning paradigm where emphasis is on learning as a result of individual cognitive processes constructing personal knowledge (cf. also Damasio, 2000; Gardner, 2003; Newell, 2009; Prince, 2004; Zull, 2002).

Based on this perspective, we support other scholars who state that the term 'organisational learning' is misguiding (i.e., Bennett and Bennett, 2008; Goldman et al., 2009; Newell et al., 2009; Stacey, 2003) because it is based on an objectified view of knowledge, stating that knowledge can be managed at an organisational level and thus stored on hard drives for future usage. This view thus devaluates the very concept of learning, because it treats learning as a manageable process controlled by others than the individuals themselves (Leonard, 1998). Instead, we claim that knowledge creation is the result of an individual learning process. Only individuals can learn, not organisations as such. Henceforth, the perspective on personal knowledge management is argued to be a key factor for successful learning in KBOs where it is stressed that only information can be communicated through phone-calls, e-mails, reports, dialogue, etc. (cf. also Kastberg et al., 2007). Then, if the employee/manager has worked actively with the information and thus created new personal knowledge based upon it, the information sharing at the organisational level is successful because new personal knowledge has been created by means of it (Davenport and Prusak, 1998; Kastberg et al., 2007; Kjelgaard, 2009; Lauridsen, 2010).

\section{Learning styles and personal knowledge management}

Because we argue that individual learning is the key element of personal knowledge management, we stress that the implementation of learning styles into organisational practice is vital. For example, Kjelgaard (2009) states that insights about individual learning strategies will create enhanced personal learning capabilities for the individuals, and it will create a mutual understanding at the organisation of how the individuals can 
work more strategically with their personal knowledge according to their individual learning styles strategies (cf. also Lauridsen, 2010). In our study, we utilised Rundle and Dunn's Building Excellence (BE) model and survey (Dunn and Rundle, 2007) as a tool to understand central aspects of personal learning in the KBO we analysed (see Figure 1 below).

Figure 1 The Building Excellence model (see online version for colours)

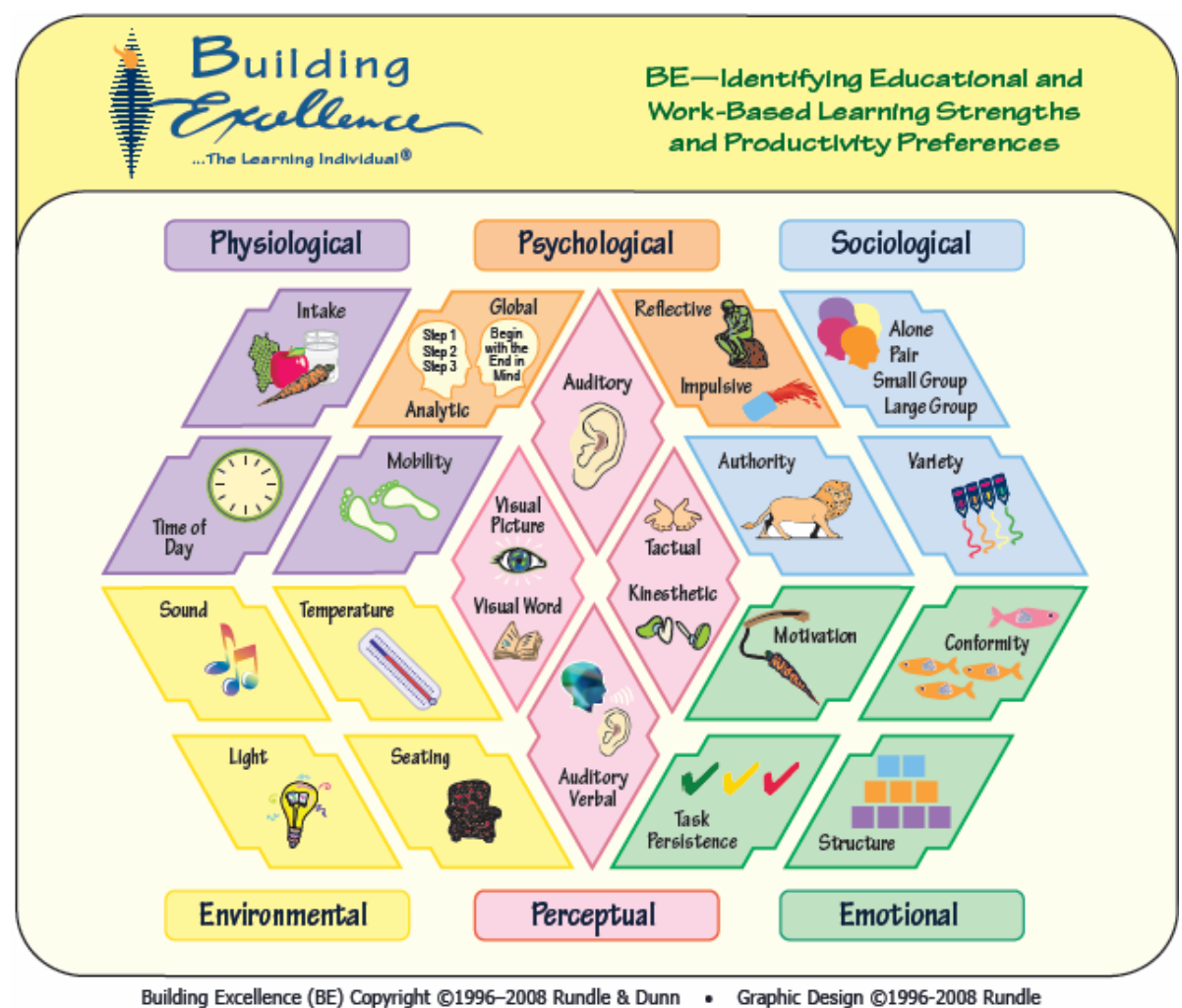

The BE model and survey are based on Dunn and Dunn's learning styles construct which is one of the most evidence-based learning styles models to date (Dunn and Griggs, 2007; Lauridsen, 2010; Lauridsen and Lauridsen, 2009). The BE learning styles model operates with six groups of elements: the perceptual, the psychological, the physiological, the environmental, the emotional and the social groups of elements. The six groups contain 20 elements with altogether 28 variables that may influence individual adult learning. This may be a positive influence when an individual exploits his/her preferences, and negative when that is not the case (Dunn and Rundle, 2007). Even though the BE model has been validated in research (Rundle, 2010), it may still be revised, e.g., as a result of the neuroscientific research conducted by Thies $(2001,2007)$. According to Thies $(2001$, 2007), the BE model addresses factors that are key to the three important functions of the brain in the individual learning process, that is, the arousal, the executive and the processing functions, thereby adding a further argument to why the $\mathrm{BE}$ model is an adequate tool in this context (cf. Bennett and Bennett, 2008; Kjelgaard, 2009). For more information about the BE, see http://www.learningstyles.net. 
In addition to the BE model, Martin Buber's philosophy of intersubjectivity (Buber, 1923 ) is applied in the inquiry as a tool needed to explain in greater detail how employees interact with one another. Buber's philosophy of intersubjectivity is an interaction dualism, or dichotomy, containing $I$ and It relationships, and I and Thou relationships (Buber, 1923; Goleman, 2006). An I and It relationship is engaged when person A uses person $\mathrm{B}$ as an object and demonstrates no personal interest or feelings. Instead, the $I$ and Thou relationship is established where interest is demonstrated, and where persons A and $\mathrm{B}$ listen to one another and both feel communion, where they are being accepted as equally important to the social construction they are part of (Bakan, 1966; Buber, 1923; Goleman, 2006). Applying Buber's dichotomy as a language tool has provided the employees with at set of terms to use when they do not feel communion during peak working periods.

\section{Unit of analysis, the case of Strategy-Lab}

Strategy-Lab was the unit of analysis in our research. It used to be a research centre run as a private professional consultancy at the Aarhus School of Business, Aarhus University (Denmark), working with the development of cutting edge business strategies, academic sparring and innovation management. The lab was supposed to generate its own funding and while the organisational setting has since changed, Strategy-Lab still spots trends and state-of-the-art practices in real life businesses, now being a fully-private consultancy which is the result if a university spin off (http://www.strategylab.dk).

\section{Research design and data collection}

The study was designed as illustrated in Figure 2 below.

Figure 2 Operational method for the clinical inquiry action research (see online version for colours)

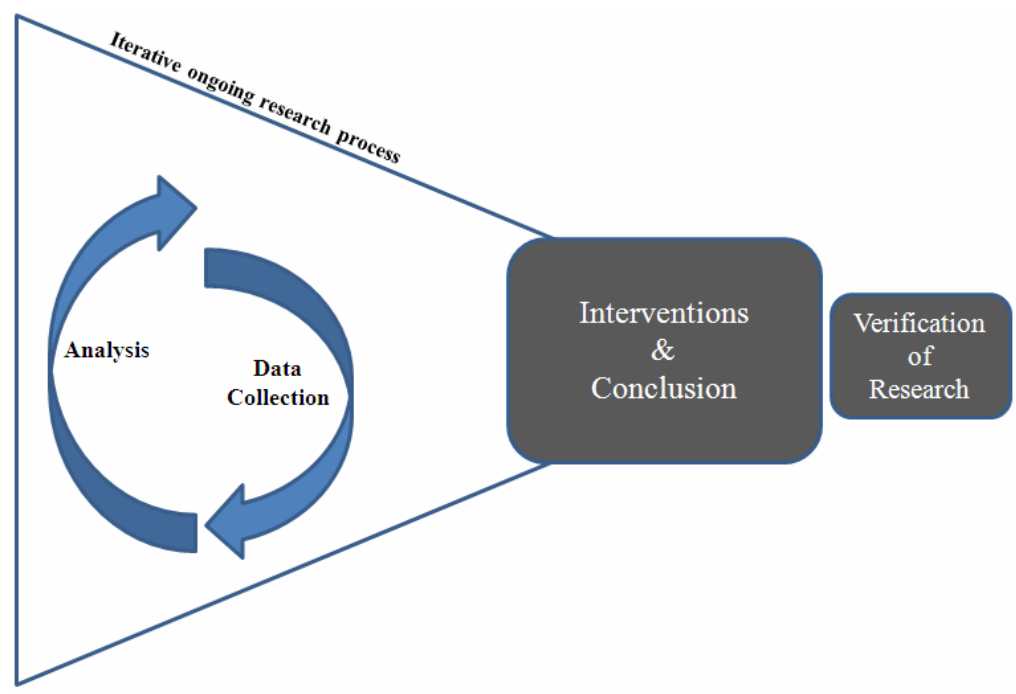


The first step of the data collection in the clinical inquiry was to observe and investigate the existing information work processes, the behaviours and the organisational culture at Strategy-Lab. In practice, we observed how the employees used the existing artefacts and how they interacted with one another (Schein, 2004). We then described our observations and took pictures (not included) to illustrate and document our findings. In the analysis we evaluated if and how the usage of the artefacts in the communication and interaction processes could be improved. We wanted to investigate if/how individual learning styles and strategies could influence the work processes at the unit of analysis, and as an intervention we asked the employees to fill out the online BE learning styles survey and read their final individual report resulting from it. The authors gained access to the individual reports, compared and analysed the individual learning styles preferences and the strategies presented in the reports of the individual team members. This analysis created valuable insights and we presented these to the employees and the management as part of our intervention. This gave the employees and the management an understanding of how to enhance their personal learning in practice and of how to work together with one another in accordance with their individual learning style preferences and strengths. To conclude our intervention we conducted emancipatory interviews and asked the individual employees about their personal opinions, attitudes and preferences regarding the analysed results of the BE Survey and the documented observations in the action research. After our analysis and intervention, some results were transferred directly to the conclusion, whereas the insights we had created that could not be validated by the research data alone, were elaborated upon and presented to the team members and the management at another critical intervention. During the second intervention, the employees discussed and reflected upon which processes and new initiatives they believed could improve the future information sharing processes and thus develop a successful strategy for individual learning, cooperation in groups/teams and thus result in organisational development. The new processes and socially created insights were transferred into the final conclusion. Finally, the clinical inquiry action research was verified by the director of the Strategy-Lab. The verification process was carried out in order to ensure the quality of the research process, and by extension to verify if it had been successfully concluded (Bradbury and Rearson, 2008; Schein, 2004).

\section{Analysis}

The analysis is summed up in three individual sections, the description and documentation of our observations, the BE learning styles results, and the emancipatory interviews.

\subsection{The observations}

Openness and special interest in the action research project was demonstrated, and the team members accepted the importance of our inquiry regarding enhanced communication and information skills. We observed that the interpersonal relations among team members were maintained by frequent face-to-face interactions. Moreover, there was an informal atmosphere where everyone was looked upon as equal, and emphasis was on informal contact when specific information was needed. Whenever the employees did not meet face-to-face, we observed that various communication tools were 
applied. The most commonly used communication channel was e-mailing. E-mails were primarily used for personal notes, sharing of general information and for planning meetings and events. Likewise, we observed that instant messaging was frequently used as a tool for conversation between two individuals when they needed to agree upon certain elements without disturbing other colleagues in the open office spaces. The phones were seldom used internally because of the close proximity of employees in the office landscapes. At meetings we noticed that there were clear differences between the employees attending. Some of them did not talk much, and others kept on talking even though something was presented by others. A couple of them often seemed restless, and when they started to rock their chairs and play with their pens, cell phones or watches, we experienced firsthand that it created a destabilised meeting environment.

\subsection{The results from the BE survey}

The analysis of the individual learning styles reports was collected into a group profile, a team mastery profile, which led to the following insights. The use of auditory information sharing media alone can inhibit mutual understanding and information processing in Strategy-Lab. Only a couple of individuals in the group have a demonstrated auditory strength. The analysis gives strong indications towards more multi-modal approaches for intra-group information sharing and personal knowledge creation, where the combination of different modes such as pictures and texts as well as tactual and kinesthetic elements are important to apply when striving for enhanced understanding and retention. The auditory verbal aspect of learning is a common strength in the group; individual team members need to express themselves aloud in order to remember and enhance their personal learning capabilities. The analysis moreover indicated that most of the employees were very tactual and kinesthetic which could explain the restless behaviour observed during meetings.

As for environmental elements, silence was needed in order to improve the information processing of team members, a challenge in the open office landscapes with much sound and disturbance. Individual adjustable lights should be present at the working stations in order to adjust the level of light to accommodate personal preferences. Additionally, a diversity of preferences was demonstrated as regards the temperature in the offices because some individuals preferred having a cooler temperature while others preferred a warmer temperature. Hence, compromises should be made in order to create an acceptable temperature for everyone involved. The team mastery profile moreover demonstrated that the conservative office schemas (Hogg and Vaughan, 2008) should be broken down because only a few of the employees are able to concentrate on complex work, when working in a chair and/or at a desk. Thus, the insights from the BE profiles demonstrated that the majority of the employees should place themselves as comfortably as possible during work. As a result, the management bought two couches and created a lounge area for reading and having meetings.

As for time of day, meetings should be held in a time slot between 10:00 AM and 3:00 PM in order to have the employees as focused as possible on their tasks, thereby allowing them to cognitively process complex information. At other times of day, it would be wise to plan routine jobs and administrative work tasks. Additionally, the results from the analysis of the team mastery profile made it clear that eating snacks 
during meetings was vital to maintain the employees' concentration; and the analysis further demonstrated that walking around while working and having meetings, thereby enhancing mobility, would also enhance the concentration among the majority of the employees and assist them in taking advantage of their personal learning styles strengths and personal knowledge management capabilities when creating new personal knowledge.

Finally, the learning styles analysis demonstrated that the team members are nonconforming, and that they prefer to create their own personal structure in the work they are doing. In addition to this, most of them have a demonstrated preference for working in pairs or small groups instead of working alone.

\subsection{Emancipatory interviews}

The emancipatory interviews were based upon questions deriving from the authors' observations during the action research and the results from the individual learning styles profiles plus the team mastery profile. This section is therefore based on the authors' insights from the learning styles analysis and the observations at the research centre.

1 The learning styles analysis

During the interviews and the analysis of the interview data, it was revealed that the employees generally believed that dialogues were the best and most time efficient way of understanding one another and thus learning from one another. This attitude could be explained by referring to the BE results which demonstrated that working in pairs was one of the great learning style preferences at the research centre, in which it is possible to reach a common understanding and thus sum up what has to be done. Moreover, we argue that when the employees work in pairs, they articulate the information aloud, which supports the auditory-verbal aspects of the perceptual elements in the BE model. Thus, according to the employees, general information sharing would be optimised if it was based on interaction and dialogue rather than one-way written communication such as e-mails, etc. Furthermore, dialogues were found to assist in creating clarity about social acceptance and validity because attention was directed at the importance of being on the right track when working on projects. Hence, the $\mathrm{BE}$ results regarding motivation, that is, the need for feedback or not, was demonstrated to have influenced the daily work processes. In addition to this, it was emphasised that being face-to-face with other colleagues was a good way to maintain personal relations, and it was the optimal way to create new personal knowledge and reflect upon work related questions. Regarding the environmental and physiological perspectives of the BE results, the employees stated that it was necessary to rethink their individual work station according to their personal learning styles profiles, because they found it imperative to minimise the inhibiting factors in their immediate surroundings, such as noise from the others in the office landscape and the perception of the right working temperature. Moreover, staff and management accepted that using the tactual and kinesthetic preferences in general should be articulated as a positive aspect of working concentrated, instead of regarding it as being unfocused and indifferent. Concerning the scheduling of meetings, the previous random selection of time was now changed, and the meetings were planned to take place during a time slot between 10:00 AM and 3:00 PM. 


\section{Observations at the research centre}

The authors' experienced a rather stressful environment during the action research period, and as a result the themes time and relevancy were two factors that were referred to constantly by the respondents during the interviews. The respondents stated that a constant time-pressure inhibited them from reflecting upon their work, and that the time pressure was a result of bad planning and the (wrong) priority given to individual tasks. Because of the perceived time pressure, team members only felt a slight need for general knowledge about other ongoing projects. Thus, the primary focus of the employees was directed at their personal projects and how these projects could be accomplished successfully. The general attitude at the research centre was illustrated by the fact that the notion of relevancy was personally determined. Sharing personal insights about feelings and emotions towards the work was not on the formal or the informal agenda of meetings. Focus was on business relevant information, and the perception of relevance at meetings was often self-centred and business related. This was primarily due to the perceived lack of time and to the economic aspect of generating an income and ensuring the survival of the research centre. As a result, some employees tended to engage in I and It relationships (Buber, 1923; Goleman, 2006). Thus, there were hardly any emotional connections during interactions, and communion was not always felt. Over time, this perceived self-centeredness could have influenced the social working environment at the research centre negatively if focus had not been directed towards a more personal interest in one another (Buber, 1923; Goleman et al., 2004). Therefore the authors stressed that team members should engage more in I and Thou relationships (Bakan, 1966; Thomas, 2009). Through the renewed attention on communion, mutual trust was kept, goodwill emerged, and a sense of being was felt. In this context, the social intelligent way of acting and thinking was articulated and found to be more effective.

The interview analysis showed that documentation of experiences and learning derived from personal insights was almost non-existing. During the interviews all employees stressed that it was imperative to pay more attention to retrospection and to creating useful documentation about the completed assignments and projects. The employees found it vital to engage in retrospection in order to be able to recreate their personal knowledge for re-usage in later projects. When asked about the reason for this lack of retrospection, the interviewees stressed that the pecuniary tradeoffs always had the highest priority, leaving out time for retrospection. Hence, there was a paradox between time for creating useful documentation to get smarter through individual and thus organisational development, and generating an income here and now for survival.

In addition to the lack of reflection and documentation, the authors observed that the focus at the research centre was not directed at organisational renewal and rethinking the business. According to the employees, the lack of introspection presented a problem. There was a clear paradox between the way the research centre was run at the time, and its mission, vision and dogmas (Overmeer, 1997). At the time of our study, Strategy-Lab's mission was to be a cutting edge collaborator and the vision was formulated as creating the future businesses by applying the newest insights. If the management continued to run the lab as observed, the research centre could risk becoming outdated in the fields of both academic and personal professional knowledge (Garrido, 2009). This concern was emphasised, because without taking the time for retrospection, documentation and gathering of new personal knowledge, e.g., from then 
latest academic journals, the mission and vision statements would become espoused theories instead of theories-in-use (Argyris, 1990). In time, the boot camp way of running the business (Mintzberg, 2000) could remove the research centre's key factor for success because no reflection and, by extension, no new learning was documented explicitly for future mutual benefit. During the interviews this fear was articulated by the team members. Moreover, the director stressed the fact that all the existing information should be consolidated and made instantly accessible. Thus, it was absolutely vital that the results of the interviews got articulated and discussed socially at the research centre. A greater mutual focus would be created if everyone agreed on the importance of these aspects. Thus, we presented the results of the inquiry and insights which we had created during our interventions and subsequently many solutions were produced through critical and constructive dialogues which we had with the employees and the management.

\section{Implication}

Our research project indicates that the focus on learning styles addresses important elements which are taken for granted but cannot necessary be so in knowledge based organisations. The results of the clinical inquiry show that focusing on individual learning strategies and optimising individual learning conditions by use of learning styles enhance not only personal knowledge management but also the amelioration of teamwork and, by extension, the emergence of incremental process innovation, that is, organisational development. Because individual learning and collaboration is the very foundation for organisational development, we set up as hypothesis that the application of the BE learning styles model can enhance individual work as well as team work in all sorts of knowledge based organisations, public or private, large or small size, etc. However, more research is needed in order to further document how Rundle and Dunn's learning styles concept (Building Excellence) may be applied in knowledge based organisations to help create functional information sharing processes and thus successful knowledge sharing.

\section{Conclusions}

According to the management and the employees at the unit of analysis, our action research project was completed successfully. The insights created by the implementation of individual learning styles and individual learning strategies created a critical discourse about the existing procedures and processes which resulted in a rethinking of the business as usual. This led to positive incremental process innovation in practice:

The implementation of learning styles resulted in a common language (a discourse) at the unit of analysis for

1 how to communicate with one another

2 how to articulate personal learning strengths and weaknesses, and thereby also creating the optimal individual learning conditions for team members both when they were working alone and when they were working together in a project team. 
In short, it was understood that there was not one correct way of working, rather it was accepted that the way in which each individual works according to his/her individual learning styles is the best way for him/her and thus for the organisation.

The focus on creating a commonly accepted perspective about individual learning as the foundation of organisational development got accepted during our research intervention. Focus was thus redirected from an objective perspective on knowledge management to a subjective learning perspective, creating attention to the fact that successful communication and personal knowledge creation occur simultaneously in practice.

The members of the unit of analysis realised the importance of exploiting individual learning style strengths and preferences, especially if/when they needed to concentrate on something complex. In addition to this, they obtained a common discourse by means of which they were able to articulate their needs and preferences. This articulation created a common understanding for e.g., why some employees became restless during meetings and needed to move around using their small and/or large motor skills when concentrating on non-routine tasks. A social intelligent way of working together was thus created by this articulation, leading to a stabilised work environment with less misunderstanding of the actions and reactions of co-workers.

In sum, the implementation of learning styles in the daily organisational practice resulted in a valuable articulation of the different needs and preferences which the employees had when working with something complex. Moreover, the results created the very foundation for enhanced collaboration as well as personal knowledge creation because of the improved intra- and interpersonal insights. As an extra feature, the social working environment was enhanced because of the socially intelligent perspective of understanding one another's actions and/or reactions when working together. The perspectives of the manager and the employees presented in this conclusion strengthens the validity of our clinical inquiry action research, which creates a novel contribution to research and practice by applying learning styles as a new dimension into organisational development in practice.

\section{References}

Anderson et al. (2004) 'The routinization of innovation research: a constructively critical review of the state-of-the-science', Journal of Organizational Behavior, Vol. 25, pp.147-173.

Argyris, C. (1991) 'Teaching smart people how to learn', Harvard Business Review, Vol. 4, No. 2, pp.4-14.

Belling et al. (2004) 'Back to the workplace: how organisations can improve their support for management learning and development', Journal of Management Development, Vol. 23, No. 3, pp.234-255.

Bennett, D. and Bennett, A. (2008) 'The depth of knowledge: surface, shallow or deep?', The Journal of Information and Knowledge Management Systems, Vol. 38, No. 4, pp.405-420.

Billett, S. (2002) 'Workplace pedagogic practices: co-participation and learning', British Journal of Educational Studies, Vol. 50, No. 4, pp.457-481.

Blackman, D. and Murray, P. (2006) 'Managing innovation through social architecture, learning and competencies: a new conceptual approach', Knowledge and Process Management, Vol. 13, No. 3, pp.132-143. 
Camuffo, A. and Comacchio, A. (2004) 'The competent middle manager: framing individual knowledge in north-east Italian SMEs', International Journal of Innovation and Learning, Vol. 1, No. 4, pp.330-350.

Crossan, M.M. and Apaydin, M. (2010) 'A multi-dimensional framework of organizational innovation: a systematic review of the literature', Journal of Management Studies, Vol. 47, No. 6, pp.1154-1191.

Daghfous, A. (2004) 'Knowledge management as an organisational innovation: an absorptive capacity perspective and case study', International Journal of Innovation and Learning, Vol. 1, No. 4, pp.409-422.

Drejer, A. (2008) 'Are you innovative enough?', International Journal of Innovation and Learning, Vol. 5, No. 1.

Eden, C. and Huxham, C. (1996) 'Action research for management research', British Journal of Management, Vol. 7, pp.75-86.

Firat, A.F. and Venkatesh, A. (1995) 'Liberatory postmodernism and the reenchantment of consumption', Journal of Consumer Research, Vol. 22, pp.239-267.

Garrido, P. (2009) 'Business sustainability and collective intelligence', The Learning Organization, Vol. 16, No. 3, pp.208-222.

Gnauer, D. (2010) 'Time to learn: exploring workplace learning affordances in a high-pressure work environment', PhD dissertation, Aarhus School of Business, Aarhus University, No. 19

Goldman et al. (2009) 'Learning in a chaotic environment', Journal of Workplace Learning, Vol. 21, No. 7, pp.555-574.

Gottschalk, P. (2006) 'Research propositions for knowledge management systems supporting electronic business', International Journal of Innovation and Learning, Vol. 3, No. 6, pp.593-606.

Higgins, D. and Mirza, M. (2010) 'Learning through work practices: mediational artifacts as a process of social learning in the knowledge-based small firm', International Journal of Innovation and Learning, Vol. 8, No. 2, pp.198-207.

Lauridsen, K.M and Lauridsen, O. (2009) 'Ny vin på gamle flasker', Dansk Universitetspcedagogisk Tidsskrift, Vol. 7. (The article has been translated with the permission of the authors as well as the editor of the journal, available in English at http://www.asb.dk/article.aspx?pid=17866).

Lee M.C. and Chang, T. (2007) 'Linking knowledge management and innovation management in e-business', International Journal of Innovation and Learning, Vol. 4, No. 2, pp.145-159.

Lehesvirta, T. (2004) 'Learning processes in a work organization - from individual to collective and/or vice versa?', Journal of Workplace Learning, Vol. 16, Nos. 1/2, pp.92-100.

Overmeer, W. (1997) 'Business integration in a learning organization - the role of management development', Journal of Management Development, Vol. 16, No. 4, pp.245-261.

Prince, M. (2004) 'Does active learning work? A review of the research', Journal of Engineering Education.

Sabri, H. (2005) 'Knowledge management in its contexts: adapting structure to a knowledge generating culture', International Journal of Commerce and Management, Vol. 15, No. 2, pp.113-128.

Schultz, K-P. (2005) 'Learning in complex organizations as practicing and reflecting: a model development and application from a theory of practice perspective', Journal of Workplace Learning, Vol. 17, No. 8, pp.493-507.

Stacey, R. (2003) 'Learning as an activity of interdependent people', The Learning Organization, Vol. 10, No. 6, pp.325-331.

Thies, A. (2001) Synthesis of the Dunn and Dunn Learning-Style Model Research: Analysis from a Neuropsychological Perspective, St. John's University Press.

Thies, A. (2007) Implications of Neuroscience and Neuropsychology for the Dunn and Dunn Learning-Style Theory, St. John's University Press. 
Thomas, R.J. (2009) 'The leadership lessons of crucible experiences', Journal of Business Strategy, Vol. 30, No. 1, pp.21-26.

Wiig, K. (1993) 'Knowledge management foundations: thinking about thinking - how people and organizations create, represent and use knowledge', Knowledge Management Series Arlington, Vol. 1.

Workman, B. (2007) 'Casing the joint: explorations by insider-researcher preparing for work-based projects', Journal of Workplace Learning, Vol. 19, No. 3, pp.146-160.

\section{Bibliography}

Anderson, W.T. (1995) The Truth About the Truth - De-Confusing and Re-Constructing the Postmodern World, Tarcher/Putnam.

Argyris, C. (1990) Overcoming Organizational Defences - Facilitating Organizational Learning, Allyn and Bacon.

Bakan, D. (1966) The Duality of Human Existence, Beacon Press.

Bradbury, H. and Rearson, P. (2008) Handbook of Action Research - The Concise Paperback Edition, Sage Publications.

Buber, M. (1923) Ich und Du essays, quoted in Goleman, D. (2006).

Burr, V. (2001) An Introduction to Social Constructionism, Routledge.

Cavaleri, S. and Seivert, S. (2005) Knowledge Leadership - The Art and Science of the KnowledgeBased Organization, Elsevier.

Correa Da Silva, F.S and Agusti-Cullell, J. (2008) Information Flow and Knowledge Sharing, Elsevier.

Da Bono, E. (1970) Lateral Thinking: Be More Creative and Productive, Ward Lock Education.

Damasio, A.R. (2000) The Feeling of What Happens - Body, Emotions and the Making of Consciousness, Vintage.

Damasio, A.R. (2006) Descartes' Error, Vintage.

Davenport, T.H. (2005) Thinking for a Living - How to Get Better Performance and Results from Knowledge Workers, Harvard Business School Publishing.

Davenport, T.H. and Prusak, L. (1998) Working Knowledge, How Organizations Manage What They Know, Harvard Business School Press.

Drucker, P.F. (1993) Post-Capitalist Society, Butterworth-Heinemann.

Dunn, R. and Griggs, S.A. (2007) 'Synthesis of the Dunn and Dunn Learning-style model research: who, what, when, where and so what?', St. John's University.

Dunn, R. and Rundle, S. (2007) Bound for Success, PCI Limited.

Easterby-Smith, M. and Lyles, M.A. (2005) Handbook of Organizational Learning and Knowledge Management, Blackwell Publishing.

Elkjaer, B. (2005) 'Social learning theory: learning as participation in social processes, Handbook of Organizational Learning And Knowledge Management, pp.38-53, Blackwell Publishing.

Eysenck, M.W. and Keane, M.T. (2007) Cognitive Psychology - A Student's Handbook, Psychology Press.

Fagerberg, J. (2005) Innovation: A Guide to the Literature, ed. Fagerberg et al. (2005) The Oxford Handbook of Innovation, Oxford University Press, New York.

Galavan, R. et al. (2008) Strategy, Innovation, and Change, Oxford University Press.

Gardner, H. (2003) Changing Minds, the Art and Science of Changing our Own and Other People's Minds, Harvard Business School Press.

Goleman, D. (2006) Social Intelligence, Bantam Dell. 
Goleman, D. et al. (2004) Primal Leadership - Learning to Lead with Emotional Intelligence, Harvard Business School Press.

Hogg, M.A. and Vaughan, G.M. (2008) Social Psychology, Pearson Education Limited.

Innovationinside (2010) 'The rise of the creative masses: transforming the workforce into an innovation force', Innovation Force, February.

Kastberg, P. et al. (2007) Personal knowledge management - Fra information til viden via læring, Samfundslitteratur.

Kaufmann, A. and Kaufmann. G. (2008) 'Psykologi i organisation og ledelse', Akademisk Forlag

Kjelgaard, J.B. (2009) 'Action research as clinical inquiry - co-creating useful changes in internal knowledge management processes', unpublished Master's thesis at the Aarhus School of Business, Aarhus University.

Klingberg, T. (2009) The Overflowing Brain - Information Overload and the Limits of Working Memory, Oxford University Press.

Kotter, J.P. (1999) What Leaders Really Do, Harvard Business School Press.

Lauridsen, O. (2010) 'Fokus på læring, om læringsstile i dagligdagen, professionelt og privat', Akademisk Forlag.

Leonard, D. (1998) Wellsprings of Knowledge: Building and Sustaining the Sources of Innovation, Harvard Business School Press.

Mintzberg, H. (2000) You Can't Create a Leader in a Classroom, Fast Company.

Newell, S. et al. (2009) Managing Knowledge Work and Innovation, 2nd edition, Palgrave Macmillan.

Pegels, C.C. (1998) Handbook of Strategies and Tools for the Learning Company, Productivity Press.

Restak, R. (2003) The New Brain - How the Modern Age is Rewriting Your Mind, Rodale.

Rundle, S. (2010) Building Excellence (BE) - The Learning Individual Research Manual, Performance Concepts International.

Scharmer, O.C. (2009) Theory U-Leading from the Future as it Emerges, Berrett Kohler.

Schein, E.H. (2004) Organizational Culture and Leadership, 3rd edition, Jossey Brass.

Stadil, C. and Waldstrøm, C. (2009) Corporate Networking, Gyldendal Business.

Tushman, M.L. and Anderson, P. (1997) Managing Strategic Innovation and Change - A Collection of Readings, Oxford.

Warburton, N. (2006) Philosophy - The Classics, 3rd edition, Routledge.

Zull, J.E. (2002) The Art of Changing the Brain - Enriching the Practice of Teaching by Exploring the Biology of Learning, Stylus. 